\title{
A Flexible E-Assessment System Inspired by Design Methodology Management to Accommodate Diverse Learning Styles
}

\author{
Tendai Dube, Minhua Ma \\ University of Derby, UK
}

\begin{abstract}
Assimilation of information varies depending on individual learners' preferences. In terms of preferred media, some learners are visual, some auditory and others kinaesthetic. In terms of thinking patterns, some are verbal/linguistic or logical/mathematical. If assimilation of information is best achieved in a particular way, achievement in assessments may also depend on how questions or tasks are set, and how learners are required to present material for assessment. In this paper, we present the design of a flexible e-Assessment system for the accommodation of the different learning styles. The design is inspired by the Design Methodology Management (DMM) technology which provides a framework for the system development. We first discuss learning styles and multiple intelligences and their impacts on learning and assessment, and then we define Design Methodology Management, and finally outline the design of the proposed flexible e-Assessment system.
\end{abstract}

\section{Introduction}

Learning and achievement in education is influenced by a number of factors which include student motivation, their interest in the subject, and also their learning styles. 'Learning styles' has become the byword in the drive to push up education standards [1] and is cited in the Governments DfES Standards documentation. Research on learning styles identifies a broad range of preferences that individual learners have for the way they assimilate information, and suggests the implications of those preferences for planning teaching, learning and assessment.

The traditional method of using learning styles in developing learning is the matching approach [2]. In essence, the use of any learning style approach or model with mixed learners is to ensure that a programme of study meets, or attempts to meet the preferences of all learners, although in any given class some preferences may not be met. Dunn and
Griggs [3] assert that the "closer the congruence between students' learning styles and their teachers' teaching styles", the higher the level of achievement. The extent of learning achieved can be realised through assessment. Therefore, it can also be asserted that developing assessments to cater for the diversity of learning styles can help students achieve high performance.

Such flexibility can be achieved through the use of technology which already plays an important role in modern education.

\section{Learning styles and multiple intelligence}

Students' learning styles significantly contribute to the way they assimilate information during the learning process. For example, some students learn better by looking at material while others learn quicker by doing.

\subsection{What are Learning Styles and Multiple Intelligences?}

James and Gardner [4] define learning styles as the complex manners in which, and conditions under which, learners most efficiently and most effectively perceive, process, store, and recall what they are attempting to learn. Stewart and Felicetti [5] define learning styles as those "educational conditions under which a student is most likely to learn." Multiple intelligence is a theory that was proposed by Gardner [6] in an attempt to accurately define intelligence thereby categorising learning styles.

There are many approaches of categorising learning styles in different domains. These include field dependent vs. field independent in the cognitive domain, visual, auditory, tactile, kinesthetic in the perceptual domain, left brain vs. right brain dominance in the hemisphericity domain, and global/analytical orientation in the psychology domain, etc.

Field dependence is the tendency to be dependent on the total field so that the parts embedded within 
the field are not easily perceived, and the total field is perceived most clearly as a unified whole [7]. Conversely, the field independent learner tends to perceive objects as separate from the field (the analytical orientation), and excels in learning which involves analysis, attention to details, and mastering of exercises, drills, and other focused activities.

Visual, auditory, and kinesthetic learning styles categories of learning styles depend on the preferred media of the learner. Visual information clearly includes pictures, diagrams, charts, plots, animations, and videos, and auditory information includes spoken words and other sounds.

Another way of looking at learning styles is to determine the learner's hemispheric dominance, i.e. is he/she more right-brained or left-brained? The left brain is the seat of language and processes in a logical and sequential order, and the right side is more visual and processes intuitively, holistically, and randomly. [8]

\subsection{Assessment of learning styles}

A learner's learning style(s) can be determined through some form of assessment. The assessment is basically in form of questionnaire type questions which are scaled. The questions are formulated in various ways but they achieve the same purpose. Some educational institutions which have grasped the impact of learning styles on the learning process have adopted these kinds of assessments. An individual's learning style is deduced from the score they get. Examples of questions of such an assessment can be as follows:

1. I feel the best way to remember something is to picture it in my head.

2. I follow oral directions better than written ones.

3. I often would rather listen to a lecture than read the material in a textbook.

Learners answer the questions against a scale like:

1. Very little like me

2. A little like me

3. Like me

4. A lot like me

\section{Learning strategies to accomplish various learning styles}

Achievement of learning objectives depends on the learning strategies employed. If students' various learning styles are considered in the learning, teaching and assessment strategies, the learning objectives can be effectively achieved.

\subsection{Learning and Teaching strategies}

One of the benefits of addressing learning styles is that students can take more responsibility for and have a deeper understanding of their learning. Also, knowledge of learning styles, learning strategies and meta cognition in a broader learning context can give teachers tools to identify the individual traits that effectively impact on achievement and give each learner the opportunity to develop through their personal strengths [9]. Table 1 shows how teaching and learning strategies can accommodate diverse learning modalities. Varying teaching strategies makes sure that students will occasionally learn in a manner compatible with their own learning preference, but it is necessary for learners to develop alternative learning strategies and thinking skills to prepare them for the tasks that require specific modalities.

\subsection{Assessment strategies}

Assessments methods emanate from the specific learning objectives of a subject, hence assessment should be included in the planning of teaching and learning. Assessments can be designed as an ongoing process (formative) or they can be designed to be used at the end of a prescribed period of learning (summative). Varying assessment strategies will also ensure accommodation of the different learning styles. Classroom presentation naturally suits verbal/linguistic learners as it requires students to verbalise their knowledge. Visual learners are likely to achieve higher in assessments which include pictures, videos, diagrams, maps, etc as those will help them figure out responses. Assessments involving analysis or problem solving will benefit logical/mathematical learners whereas kinaesthetic learners will do well in fill-ins and multiple choice questions.

\section{Flexible E-Assessment}

The growth of technology is evident in the field of education where its use is almost inevitable in the delivery of learning materials. E-learning, which is the acquisition of knowledge and skill using electronic technologies like computers and the Internet, has become dominant in Higher Education. One of its domains, e-assessment, is gradually becoming more preferable than the traditional pen and paper method of assessment.

\subsection{E-Assessment}

E-Assessment is one of the domains of e-learning. It refers to assessment which is electronically 
delivered. The Joint Information Systems Committee (JISC) defines e-assessment as the end-to-end electronic assessment processes where Information and Communication Technology (ICT) is used for the presentation of assessment activity, and the recording of responses [10]. Figure 1 shows the different categories of assessment [11].

Table 1. Teaching and learning strategies for various perceptual learning styles

\begin{tabular}{|l|l|}
\hline Visual learner & $\begin{array}{l}\text { Draw a map of events, diagrams, and } \\
\text { figures; Make outlines } \\
\text { Copy what's on the board Take } \\
\text { notes, make lists Uatch videos } \\
\text { Colour code words and notes } \\
\text { Outline reading Use } \\
\text { flash cards } \\
\text { highlighters, circle or underline words }\end{array}$ \\
\hline $\begin{array}{l}\text { Auditory } \\
\text { lverbal) }\end{array}$ & $\begin{array}{l}\text { Using word association to remember facts } \\
\text { and lines Recording lectures } \\
\text { Watching videos Repeating facts } \\
\text { with eyes closed } \\
\text { Participating in group discussions } \\
\text { Using audiotapes, taping notes after } \\
\text { writing }\end{array}$ \\
\hline $\begin{array}{l}\text { Kinesthetic } \\
\text { learner }\end{array}$ & $\begin{array}{l}\text { Studying in short blocks Taking lab } \\
\text { classes Role playing } \\
\text { Taking field trips, visiting museums } \\
\text { Studying with others Using memory } \\
\text { games Using flash cards to memorize } \\
\text { Using short definitions, fill-ins \& multiple } \\
\text { choice in tests }\end{array}$ \\
\hline
\end{tabular}

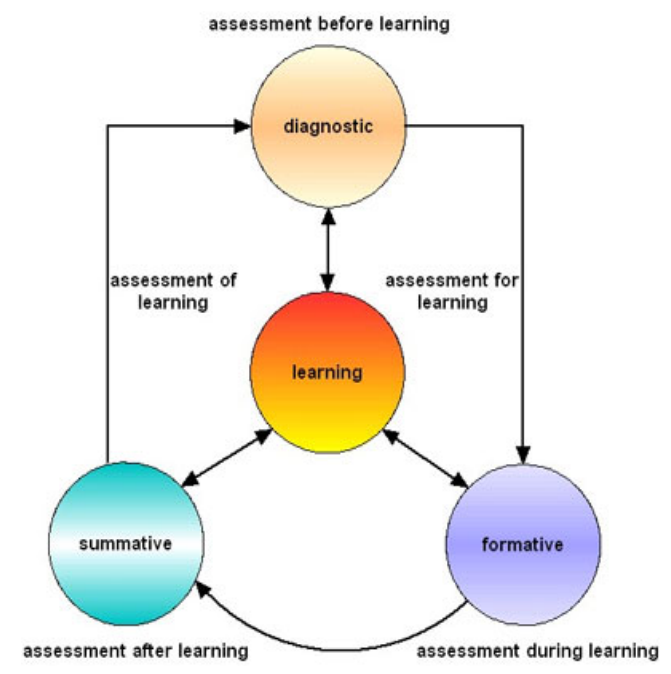

Figure 1. Categories of assessment
In the education field, any type of assessment is related to learning. It can be done prior to provision of learning to determine what is already known by a student, that is diagnostic. Formative assessment checks how much has been assimilated during the learning process whereas summative assessment, which comes after the learning process, tests to see if learning objectives have been achieved.

\subsection{How the learning styles impact on the design of assessment?}

Once the different learning styles of learners are identified using a diagnostic questionnaire, assessments can be designed in such a way as to accommodate that diversity. The different question types render themselves suitable for that purpose. These include multiple choice, text entry and gap filling, drag and drop, as well as graph questions. Eassessment systems can accommodate these question types and hence the systems can be designed in such a way that learners can be assessed on the same skill or objective but using different assessment question types as demonstrated in the case study.

\subsection{A case study}

A couple of questions are presented here in the different ways they could be set to accommodate the diverse learning styles. They are taken from some developed assessments in Biology of Organisms and Data Analysis.

\section{Question type 1:- Text Entry}

The diagram below represents the longitudinal section of a flower. Identify the features highlighted.

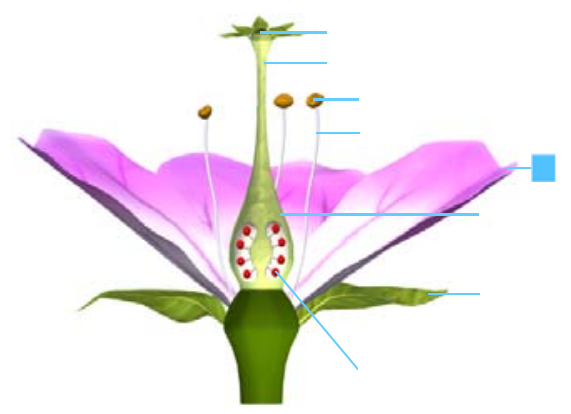

In this case students enter the text to identify the highlighted features. 


\section{Question type 2:- Drag and drop}

Move the given labels to the correct positions to identify the highlighted features of the flower.

Labels:

\begin{tabular}{|l|l|l|l|}
\hline Anther & Style & Receptacle & Sepal \\
\hline Stigma & Ovary & Filament & Petal \\
\hline Ovule & \multicolumn{2}{l}{} \\
\hline
\end{tabular}

In this question type, students are given the answers but they need to remember the correct positions to place them on the diagram.

\section{Question type 3:- Unguided Text Entry (without the picture)}

List the nine major parts of a flower.

\section{Question type 4:- Multiple choice}

Which of the following is represented in the graph below?
a. $x=2-1 / 5 y$
b. $y=2-1 / 2 x$
c. $\mathrm{y}-2=1 / 2 \mathrm{x}$
d. $y=10+5 x$

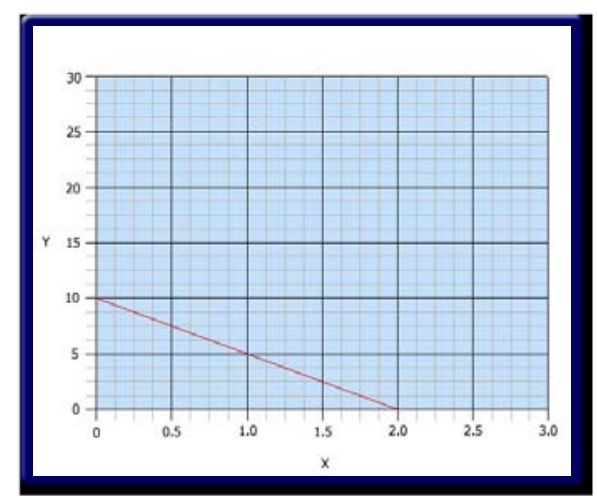

\section{Question type 5:- Sketch}

Draw a line on the graph to represent $\mathrm{X}=2-1 / 5 \mathrm{y}$

Visual learners are likely to do well in the sketching question, and in the multiple choice question. The given graph may help them work out and select its correct representation.

\section{Design of the Flexible E-Assessment System}

The design of the flexible e-assessment system is inspired by Design Methodology Management
(DMM) technology. The three key words: Design, Methodology, and Management which form this technology need to be understood before one understands DMM itself. Some definitions and descriptions of these from research are outlined below.

\subsection{Definition of DMM}

Zhu [12] identifies two facets of Design as: firstly, a plan to bring about man-made product, with that plan aiming to achieve a prescribed goal and satisfy certain constraints; secondly, a process of the creative development of such a plan. He goes on to specifically define Engineering Design as the use of scientific principles and technical information in the creative development of a plan to bring about a manmade product to achieve a prescribed goal with certain specified constraints. In the same vein, Software Design is deemed a branch of Engineering Design where the product to bring about is software.

Methodology refers to "the processes, techniques, or approaches employed in the solution of a problem or in doing something: a particular procedure or set of procedures" [13]. Fiduk [14] defines methodology as a sequenced set of operations employed in performing a particular function such that, given a methodology, the function can be performed in a predictable and repeatable way. Baldwin [15] defines methodology as the sequence of tools, and he defines methodology management as the functionality of selecting and executing the tools.

Kalavade [16] states that a design methodology specifies a sequence (flow) of tools that operate on data. In the light of that description, he perceives that DMM deals with data, tool and flow management. McKnight [17] defines Design Methodology as a sequence of activities required to get from one stage of the design process to another, summing it up as: Design Methodology $=$ Tool Set + Design Flow + Constraints (i.e. its customization).

Design Methodology Management (DMM) deals with the execution and control of methodologies used in the design process, in a flexible and configurable way. In other words DMM deals with the execution and control of the tools and tasks used in the design process. McKnight [17] defines it as the management of a design methodology's component parts, i.e. management of the toolset, the design flow and any required constraints or customizations. It addresses the need to manage the manner in which design tools are executed to achieve a desired function.

The Design Management Technical Subcommittee (DMMTSC) of the Computer Aided Design (CAD) Framework gave definitions of the terms that feature 
in the description of DMM given above [14]. A tool is defined as a single executable program capable of performing a specific design function. A process is a combination of tools and/or other processes that perform a design function. A task is described as an abstraction of a design function, for example, simulation. Lastly, methodology is seen as a sequence of these tasks. Figure 2 summarises these descriptions thereby forming a Design Methodology Management framework.

\subsection{Requirements of a Methodology Management system}

From the given definitions above, three main components of DMM are identified as tools, tasks, and execution and control.

Tools need to be described and executed in a manner that is generic and extensible. The descriptions must be complete enough to meet the requirements for executing the tool. Users do not need to know the details of tool execution. Tool description must include data requirements, argument definitions, interactive tool command set characterization, resource requirements as well as function description.

A designer must be able to construct short sequences of tools dynamically for debug purposes. Task descriptions must support sequencing of tools to be executed within the task; intra- and inter-task dependency definitions, e.g. output and input data relations; flow control constructs such as conditional

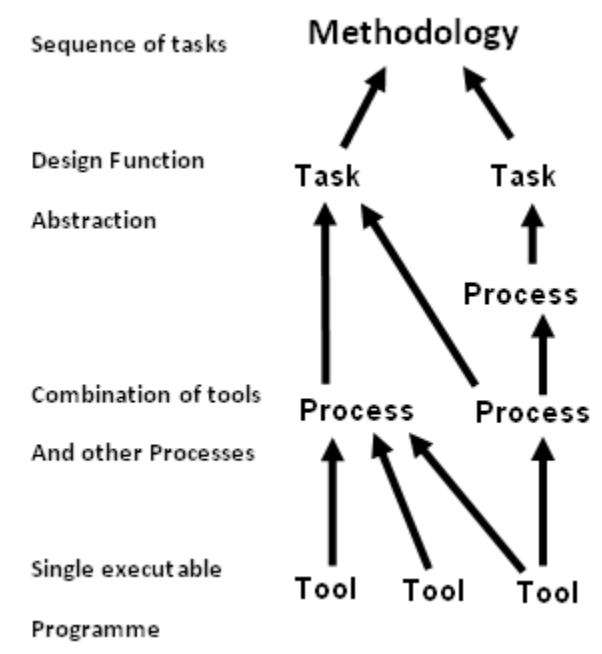

Figure 2. Design Methodology Management Framework

branching, selection and iteration and also task portability to different design environments.
Users must be able to invoke tasks and tools, and monitor their states. This includes among other things, tool selection, automatic tool invocation, tracking and displaying the state of the task including the state of all related processes, recording all user interaction and tool and task processing, suspension and resumption of task execution, supporting queries on tool and task execution status and history and also back tracking and error recovery.

\subsection{Application of DMM in Computer Aided Design}

Design Methodology Management has largely been applied to the field of Computer Aided Design (CAD) but it can also be applied to other fields of design like mechanical design and software design. There are many ways DMM can be employed to systems design. One way it has been used in CAD was designing using process flow graphs.

A process flow graph is used to describe the flow of information in a design process. Formally, the graph can be represented in the form,

$\mathbf{G}=(\mathrm{T} ; \mathrm{S} ; \mathbf{E})$, where

$\mathbf{T}$ : is the set of task nodes, represented by circles.

S: is the set of specification nodes, represented by rectangles.

$\mathbf{E}$ : is the set of edges indicating which specifications are used and produced by each task, represented by unidirectional arrows.

Figure 3 [18] is an illustration of a process flow graph showing these representations. The graph has Behavioural Description specification as input that is processed to produce a Structural Description specification as output. Processing includes the tasks Compile, and Schedule and Allocate which respectively produce control-data flow graph (CDFG), as well as a schedule table and a functional unit allocation table.

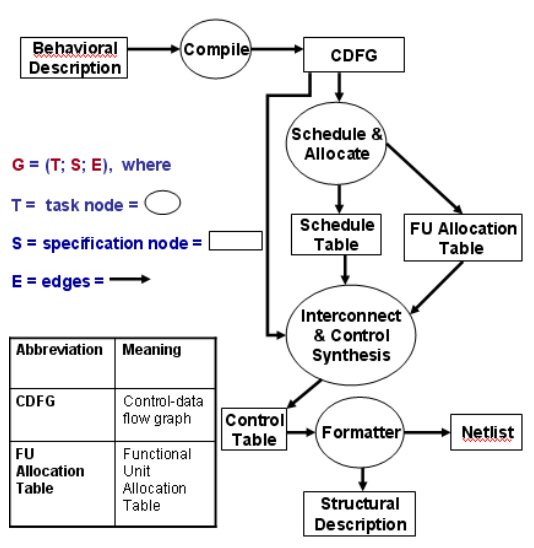

Figure 3. Process Flow Graph 


\subsection{Technical requirements of modern E- assessment}

Due to the variety of e-assessment systems serving different purposes, technical requirements of such systems can also vary. However, as the medium of delivery converges, there are basic technical requirements that should be met by all e-assessment systems. Literature review was conducted to identify common technical requirements of modern eassessment systems.

Key areas of technology in e-assessment are identified in literature as: software; connectivity and bandwidth; data storage and transfer; security; accessibility; and lastly technical standards. The eassessment runs from software installed on a computer and connection speeds to the Internet need to be considered. Security is regarded as of prime importance in the management of e-assessments as outlined in British Standards [19]. This includes security issues of privacy, confidentiality, authentication and transfer of data.

Other requirements relate to the platform on which the e-assessment runs. One of the drawbacks of eassessment systems has been identified as being platform specific and having limited cross-vendor interoperability [20]. Standards in e-learning endeavour to ensure interoperability, portability and reusability of content and systems (Friesen, online). Since modern e-assessment can ideally be taken any time anywhere, it is essential that software run on any operating system.

Another requirement is the provision of adequate navigational facilities. Assessment software should provide simple, clearly explained and consistent navigational facilities that allow the candidate to navigate through the items in the assessment as freely as permitted by the assessment regulations [20].

An assessment system loses its purpose if learners find it difficult to use. Usability of the assessment system is of paramount importance in the effectiveness of the assessment delivery. Considerations should be made to match design to the user needs, user control over presentation where applicable, consistent navigation, functionality, positioning and names of buttons and icons, and also alternative input or navigation methods where practicable.

\subsection{A Flexible E-assessment System requirement Model based on the DMM technology}

Following the creation of the generic model, Figure 2 in section 5.1, an e-assessment system requirement model was established based on the Design Methodology Management technology. This was achieved by mapping the requirements of the desired flexible e-assessment system to the generic model.

\section{Requirements of a Flexible E-assessment System}

The flexible e-assessment system is for use in any subject area for formative assessments to enable students to practice their learning material. Students are first given questionnaire type questions from which their learning styles can be determined. The system records the students' responses and identifies their respective learning styles. Depending on the dominant learning style, the system then presents the student with assessment questions (for the formative assessment) which are suitable for their learning style. The system records, and automatically marks the students' responses. The students can view the correct answer if they answer a question wrong and they can also see the overall score for the assessment.

\section{The Model}

Figure 4 represents the established e-assessment DMM design model derived from the requirements of the collaborative e-assessment system and informed by the requirements of a methodology management system. At the top level, tasks act as the objectives of the design as design work is undertaken in order to achieve some objectives. At the base of the model are the tools needed in order to achieve the tasks. When the tools are selected, some processing goes on within the system towards the achievement of those tasks. The design apparently matches design methodology systems as summarised in figure 5 .

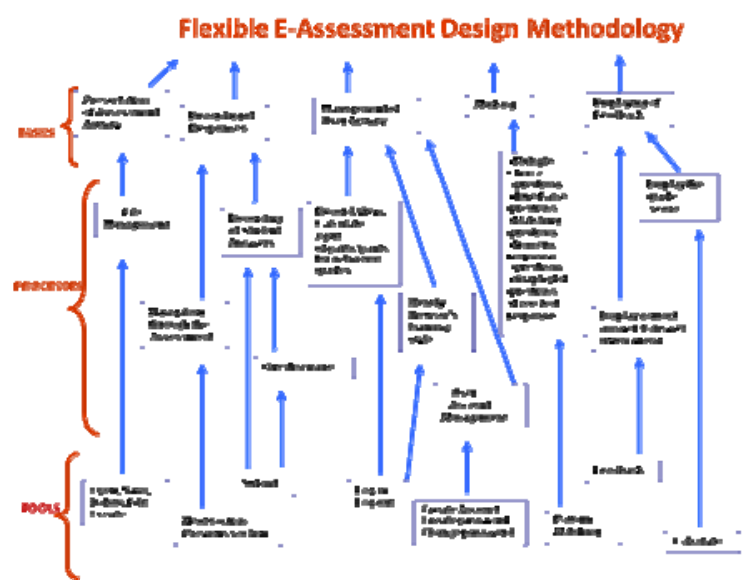

Figure 4. E-assessment DMM design model 


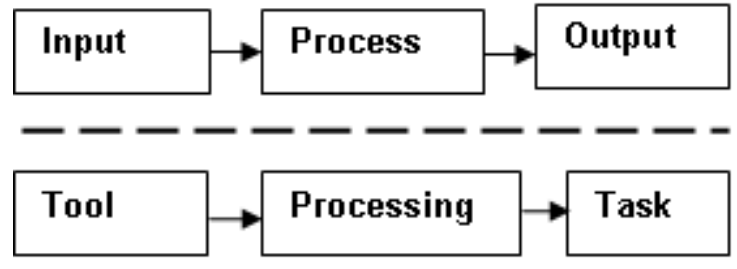

Figure 5. Design methodology system

Using the formalism of $\mathrm{D}=(\mathrm{T} ; \mathrm{S} ; \mathrm{E})$ as discussed in 3.3, a process flow graph can also be drawn for the eassessment system. Figure 6 illustrates a simplified representation of the system following the CAD example in Figure 3.

\subsection{Implementation of the design}

DMM renders itself to a modular approach to system development and as such, a component of the system as modelled in Figure 4, has already been implemented to demonstrate the effectiveness of this methodology. The system is developed using the Hypertext Pre-processor (PHP) scripting language and MySQL database which come bundled in the open sourced Wamp Server version 2 on which the system runs. Wamp Server is a mini-server that can run on Windows Operating System. It also comes bundled with Apache version 2.2 which is software that runs web services. PHP is a general-purpose scripting language suitable for the development of dynamic and interactive web pages and applications. Administration of the MySQL database is done through the use of phpMyAdmin which is software tool written in PHP.

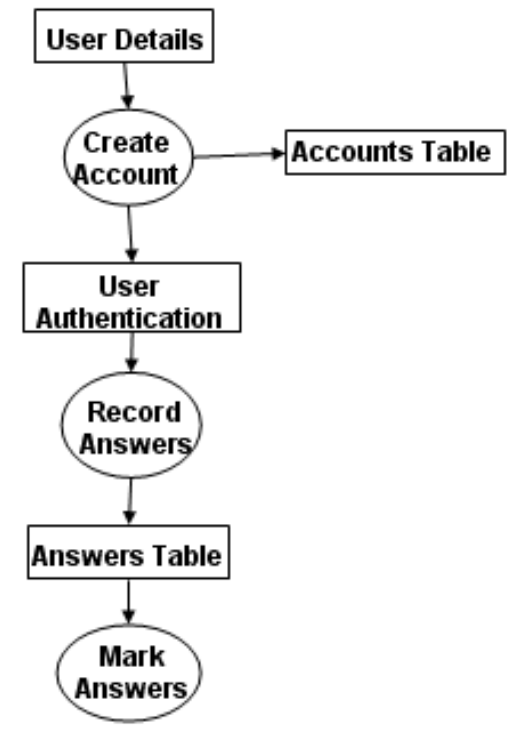

Figure 6. E-assessment Process Flow Graph
Due to the nature of the development environment described above, all tasks, except the feedback component, have been represented in the implementation. However, the main focus so far has been on the tasks of Presentation of Assessment Activity and Recording of Responses. A database consisting of four tables was created through the phpMyAdmin interface to hold and store information for the running of the flexible e-assessment. Figure 7

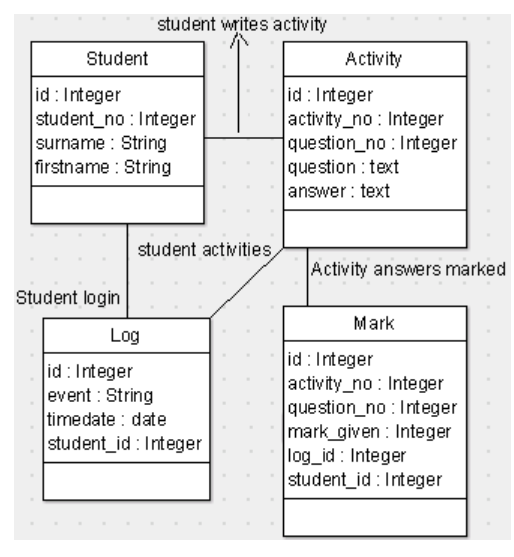

Figure 7. Database Model

shows the tables with their respective fields and how they relate to each other.

The activity table holds the questions to be presented to the students as well as the answers to those questions for marking purposes. The log table stores date and time entries when users interact with the system, e.g. registering or logging on, submitting responses and completing the assessment as shown in figure 8. The mark table records the answers given by the students for the different questions and also the marks the system gives them on each question. The student table stores information about the registered students so that their relevant interactions with the system can be accurately recorded and their marks given accordingly.

When the assessment is running, on the first web page, the students fill in a form to register their personal details, e.g. name and candidate number, so that they can be uniquely identified by the system. If they would have previously registered, they can just $\log$ in with their student number. The details are recorded and stored in the MySQL database in the student table. The next page displays the instructions for the students to follow, and also links to the various sections of the assessment. Figure 9 is an example of that page.

On clicking an assessment activity, the students are presented with the questions for that activity one by one and they are given a text entry box to enter their answers. When the Submit button is pressed, 


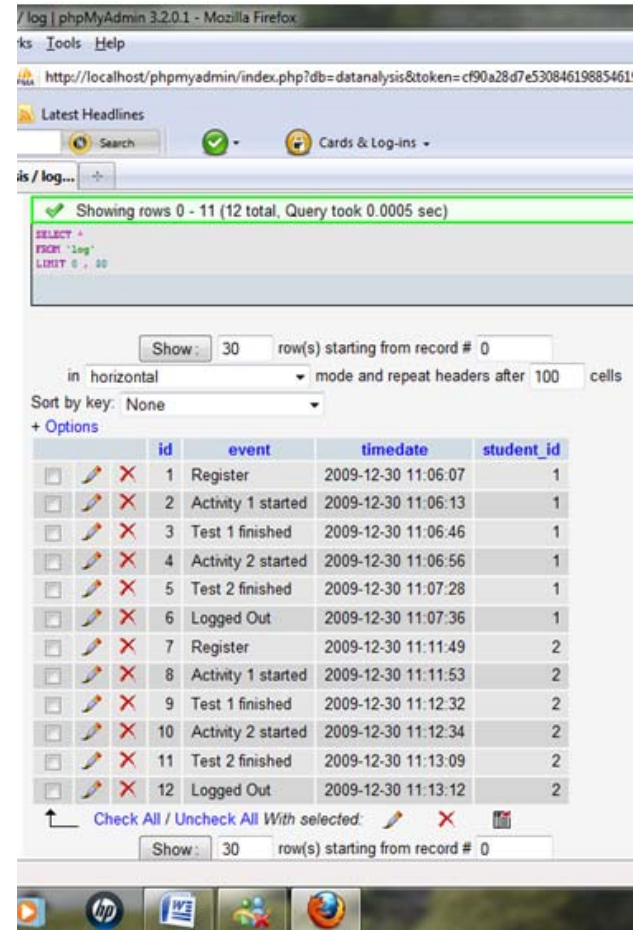

Figure 8. Log table screen

the answer entered is recorded in the database in the mark table and a mark is given for it accordingly, and then the next question for the current activity is presented. Figure 10 demonstrates the presentation of the assessment activities at a certain point. It should be noted that, it is just short text entry question type that has so far been implemented for demonstration. Other question types like true/false or multiple choices, as listed in figure 4, are in development.

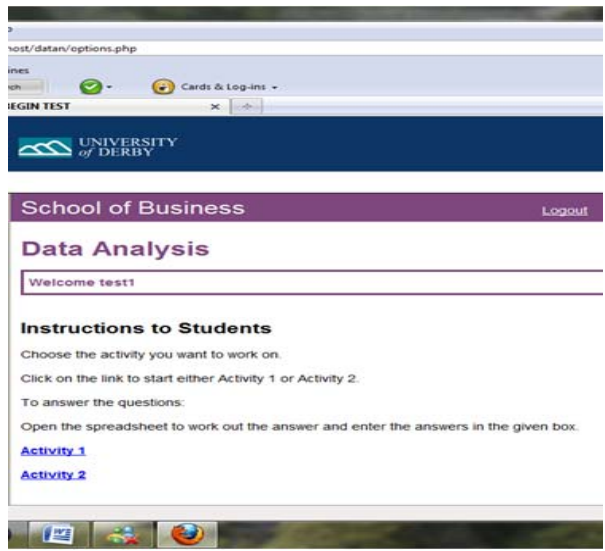

Figure 9. Instructions and assessment activity links

\section{Conclusions and Future Works}

The versatility of e-assessment systems makes it possible to accommodate the different learning styles in assessments. This provides a flexible strategy to assessment leaving the learners in charge of their achievements. While it may not be possible to accommodate every learning style in any given assessment, the variety of question types, makes it possible to cover a wide range.

The flexibility of Design Methodology Management makes system design an easy and straight forward endeavour. The clear structure of the framework is excellent for traceability of the assessment process during the development of the system. Hence it ensures all requirements are captured. This paper is only a snapshot of the potential of DMM to the development of eassessment systems. The full potential of this technology will be realised when all parts of the system have been developed.

For future work, we plan to continue with the implementation of the flexible e-assessment system. A diagnostic assessment will be included in the database in order to identify the students' learning styles. Different question types will be developed including free-text response questions. The various question types will be mapped to the different learning styles and the system will automatically present the relevant questions for the identified

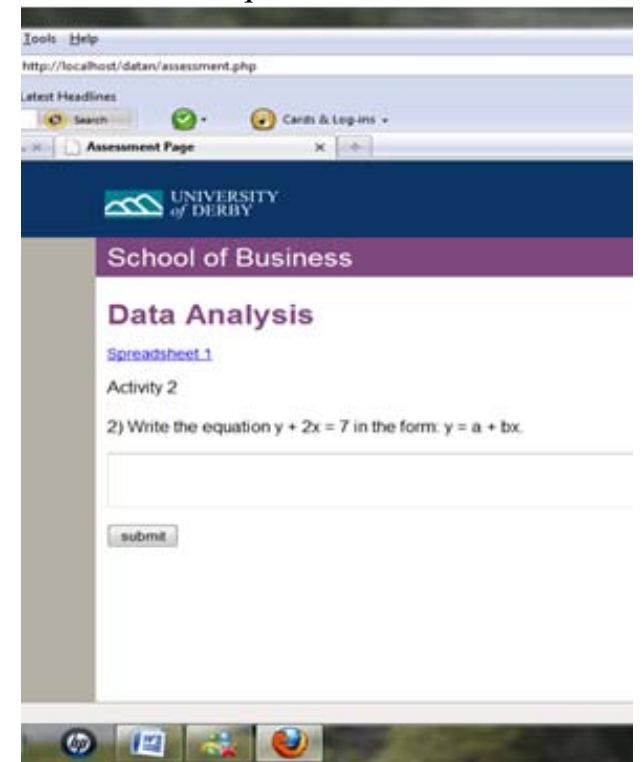

Figure 10. Activity 2 Question 2

learning styles. Adaptive assessment based on the Item Response Theory will also be investigated in the future. 


\section{References}

[1] Franklin, F. (2006) VAKing out learning styles — why the notion of 'learning styles' is unhelpful to teachers, Education 3-13,34:1,81 - 87

[2] Pheiffer, G., Holley, D. and Andrew, D (2005) Developing thoughtful students: using learning styles in an HE context, Education \& Training, Vol. 47 No. 6, pp. 422-431

[3] Dunn, R and Griggs, S. A. (2000) Practical Approaches to using Learning Styles in Higher Education. Bergin: Westport

[4] James, W. B., and Gardner, D. L. (1995) 'Learning Styles: Implications for Distance Learning', New Directions for Adult and Continuing Education, vol. 67, Fall 1995, pp. 19-32.

[5] Stewart, K. L., \& Felicetti, L. A. (1992). Learning styles of marketing majors. Educational Research Quarterly, 15(2), 15-23.

[6] Gardner, H. (1993) Frames of mind: The theory of multiple intelligences. New York: Basic Books.

[7] Brown, H. D., (1994) Principles of Language Learning and Teaching (3rd ed.). Englewood Cliffs, NJ: PrenticeHall, Inc.

[8] Hopper, C. H., (2007) Practicing College Learning Strategies, 4th ed., Houghton Mifflin.

[9] Bostrom, L. and Lassen, L., M. (2006) Unraveling learning, learning styles, learning strategies and metacognition, Education \& Training, Vol. 48 No. 2/3, pp. 178189

[10] JISC, (2007) Effective Practice with e-Assessment; HEFCE, $\quad$ online, http://www.jisc.ac.uk/media/documents/themes/elearning/e ffpraceassess.pdf (6 May 2007)

[11] Crisp, G., (2008) Interactive eAssessment. http://online.waikato.ac.nz/blog/, (10 April 2009)

[12] Zhu, H., (1995) Software Design Methodology: From Principles to Architectural Styles, Butterworth-Heinemann.

[13] Kleinfeldt, S. et al., (1994) Design Methodology Management, Proceedings of the IEEE, Vol. 82, No. 2, February 1994 pp. $231-250$.

[14] Fiduk, K. W. et al., (1990) Design Methodology Management, A CAD Framework Initiative Perspective. Proceedings of the 27th ACM/IEEE conference on Design automation, Orlando, FL, USA. pp. 278 - 283.
[15] Baldwin, R. A., (1995) A Formal Approach to Managing Design Processes, Computer, Feb 1995, Volume 28, Issue 2, pp 54-63.

[16] Kalavade, A. J., (1995) Managing Complexity In Heterogeneous System Specification, Simulation, And Synthesis. Proceedings of the International Conference on Acoustics, Speech, and Signal Processing (ICASSP), Detroit, Michigan, May, 1995, pp. 1125-1128

[17] McKnight, A., (1991) Flexible Design Methodology Management, Design Management Environments in CAD, IEE Colloquium on, Volume, Issue, 31 Jan 1991 pp. 1/1 $1 / 6$.

[18] Baldwin, R., \& Chung, J. M., (1994) Design Methodology Management Using Graph Grammars, Proceedings of the 31st annual Design Automation Conference, pp $472-478$.

[19] British Standard, (2007) Information Technology - A code of practice for the use of information technology (IT) in the delivery of assessments. BSI

[20] Whitelock, D. \& Brasher, A., (2006, June). A roadmap for e-Assessment; http://kn.open.ac.uk/public/workspace (12 July 2008) 